\title{
Unconscious elements in linguistic communication: Language and social reality
}

\section{ABSTRACT}

The message of the present article is, first, that, besides and below the strictly linguistic aspects of communication through language, of which speakers are in principle fully aware, a great deal of knowledge not carried in virtue of the system of the language in question but rather transmitted by the form of the intended message, is imparted to listeners or readers, without either being in the least aware of this happening. For example, listeners quickly register the social status, regional origin or emotional attitude of speakers and they react to those kinds of 'paralinguistic' information, mostly totally unawares. When speaker and listener have a positive attitude with regard to each other, the reaction consists, among other things, in mutual alignment or accommodation of pronunciation features, lexical selections and style of speaking. When the mutual attitude is negative, the opposite happens: speakers accentuate their differences. Then, when this happens not between individual interlocutors but between groups of speakers, such accommodation or divergence phenomena may lead to language change. The main theoretical question raised, but not answered, in this article is how and at what point forms of behaviour, including linguistic behaviour, achieve the status of being 'standard' or 'accepted' in any given community and what it means to say that they are 'standard' or 'accepted'. It is argued that frequency of occurrence is not the main explanatory factor, and that a causal explanation is to be sought rather in the, often unconscious, attitudes of individuals, in particular their desire or need to be integrated members of a community

\section{KEYWORDS}

accommodation consciousness divergence frequency group identity social reality 
or social group, thus ensuring their safety and asserting their group identity. The question thus belongs to the province of social psychology. Qualms about analyses of this kind being 'unscientific' dissipate when it is realized that consciousness phenomena are part of the real world and must therefore be considered to be valid objects of scientific theory formation. Like so many other ill-understood elements in scientific theories, consciousness, though itself unexplained, can be given a place in causal chains of events.

\section{THE UNCONSCIOUS MACHINERY OF LANGUAGE}

Before broaching the topic of unconscious elements in linguistic communication, it is useful to have a quick look at the unconscious nature of language itself - a fact that has been unearthed in theoretical linguistics over the past half century. In linguistics, a distinction is made between language and speech. The distinction goes back to the Swiss linguist Ferdinand de Saussure (18571913), who introduced it in his posthumously published Cours de linguistique générale/Course in General Linguistics of 1916. When we say 'speech' (de Saussure's parole), what is meant is the active or passive use of a natural human language in whatever medium. In the active sense, it can be speaking, writing or gesturing in a gestural language, such as a language for the deaf. In the passive sense it can be understanding through the perception of linguistic sounds or the reading of texts or the interpretation of linguistically organized meaningful gestures. The term speech (parole) is thus used in the wide sense of the actual, physical production and interpretation of linguistic signs. Analogously, we, linguists, use the term speaker or speaker/listener, for a person who produces and/or interprets linguistic output. Only when the context calls for greater specificity do we use the more specific terms writer, listener, reader or speaker sensu stricto.

It is commonly accepted in linguistics that speech, in the wide sense, is possible only because speakers have at their disposal an unconscious mental or cognitive, machinery of great complexity, enabling them to produce and interpret linguistic signs. That system we call language (de Saussure's langue) when we speak about it in general terms, and a language when we refer to a specific language as an accepted medium of communication in any given language community. The French use the term le langage for the whole complex of language and speech together. In English, there is no special term corresponding to le langage; we just do with language.

The ontological status of any specific language or language variety is that it is part of social reality. Although de Saussure already stated that 'Language [langue] [...] is a grammatical system virtually existing in each brain, or, more precisely, in the brains of a totality of individuals; for language is not complete in any single brain, it exists perfectly only in the mass of speakers' (1916: 30 ), the insight that the ontological position of any specific language qua language is in social reality has not, on the whole, made its way into professional linguistics. During the mid-twentieth century it was customary, even trendy, to speak of a language as an unrestricted set of actually made utterances, thereby placing any specific language in physical reality, considered, then as now, to be the safest ontological haven. After that, it became current practice to place language in mathematical reality, as if a language were a mathematical system. This was actually propagated in straightforward terms by the Californian mathematical logician Richard Montague (1930-1971), who 
gained a large following with his theory of model-theoretic formal semantics. This form of semantics is nothing but a somewhat excentric branch of mathematics, little to do with language as a phenomenon in the rich ecology of world, mind and society (see Seuren 2013, Chapter 9). During that period, the same idea was put forward, though in much more hesitant terms, by Noam Chomsky (b. 1928) in his theory of generative grammar. For him and his followers, a language is a set of sentences and a sentence is a string of symbols generated by an algorithmic production system of formal rules defining well-formedness over strings of symbols. Although Chomsky holds that such a generative system should be taken to be a theory of the native speaker's linguistic competence, he has never been clear on whether such a theory should be taken in a realist or a merely mathematical or instrumentalist sense. Sometimes it is the one, sometimes it is the other.

All this, however, is irrelevant; it only serves to illustrate how afraid the 'scientific' community is of dealing properly with questions regarding the mind or social reality, both considered to be unsafe ontological havens. The simple truth is that any specific language is, to begin with, a mental or cognitive vehicle for the systematic expression of intended meanings. These meanings consist of a socially committing operator over a proposition $p$, whereby the speaker guarantees or suggests the truth of $p$, or requests the listener to provide the truth value of $p$ (yes/no-questions) or the value of a parameter in $p$ (so-called WH-questions), or orders the listener to make $p$ true, and various variations on these themes (see Seuren 2009, Chapter 4, 'Speech acts'). This cognitive 'vehicle' has been accepted, approved and made their own by the collective members of a speech community, who consider it to be their language. It is this acceptance by a speech community that makes a language the language it is, defining as it does the lexicon, the grammar, the phonology and the phonetics of the language in question. Thus, when it is said that any specific language (not 'language' in a general sense) is part of social reality, it is implied that it is also part of cognitive reality, in that there is no social reality without cognitive reality.

That given words and sentences mean what they mean is due to the 'will of the people', which reigns supreme over any norm system valid within and for a community, within the limits set by the physical and cognitive environment in which the norm system is meant to operate. In the case of language, this norm system is to a large extent unconscious. The lexicon is not. Most of the lexicon is open to awareness, or else it would be impossible to select the proper lexical items for the expression of any given meaning. But the processes whereby sentences are constructed and pronunciations are chosen and realized take place below any threshold of awareness and are thus unconscious.

The relation between speech and language is comparable, to some extent, with that between the use of a computer on the one hand and the complex software and hardware systems inside the computer on the other. Computers have been designed to be maximally user-friendly, so that the user does not have to bother about what happens 'behind the screen'. In the same way, speakers do not have to bother about what happens 'below the surface'. Their 'screen' is, essentially, the interface created by possible consciousness or awareness. There are various places in the production and reception systems involved in linguistic interaction where the speaker/listener can make himself aware of what is going on. ${ }^{1}$ This does not mean that he is always actually aware of what will appear on the consciousness screen if he 'requests' for it to appear, but it does mean that he can make himself aware of that and that he 
knows that. Frequency of use, together with the peripherality of the thought processes involved, quickly leads to routine formation, but the possibility to stop and reflect at the assigned interface levels, for purposes of control or further reflection, is always there.

It is true, of course, that we have not so far developed a scientific theory of consciousness - perhaps the most central difficulty in cognitive science and related fields. This does not mean, however, that science has no grip on phenomena that involve or are dependent on consciousness. All that is needed is a 'clause' in the charter of science to delimit and encircle the blank consciousness spot on the map. In other words, one can 'package' consciousness as if it were a black box and let it play its part in scientific theory formation, leaving the unpacking to later, if ever. The recognized 'sciences', however, have so far been reluctant to take this step.

In Seuren (2009: 253) it is proposed that in speech - the use of language the language machinery makes available five 'gates' or 'interface levels' to the speaker/listener. These interface levels are formulated in terms of the speaker sensu stricto, but they are valid also for the listener, since we know that utterance interpretation is a process that involves a multiplicity of possible control feedbacks, all of which follow the production path as they are based on a hypothetically posited interpretation whose output is then rapidly checked for conformity with the output received - the so-called analysis-by-synthesis method. The five interface levels proposed are:

1. The INTENT level, where the speaker checks the semantic input to the language machine: is this what I want to say?

2. The LEXICAL level, where the speaker checks the lexical selections made: are these the words I want to use?

3. The SURFACE level, where the speaker checks the lexico-grammatical structure of the output in preparation: is this a correct and clear rendering of what I intend to say?

4. The INTERNAL PERCEPTUAL level, where the speaker checks the 'phonetic plan' for the utterance in preparation: are these the right recipes for the physical realisation of my planned utterance, properly adapted to audience and situation?

5. The EXTERNAL OUTPUT level, where the speaker checks the actually realized output in hindsight, so to speak: does this correspond to what I had in mind to say and how I wanted to say it, or do I have to correct it?

At these five places in the production process the speaker sensu stricto can, if he wishes, stop and carry out a control check in full consciousness, even though in most cases the process is skipped. ${ }^{2}$ The stages between these interfaces are taken to be fully automatized and totally inaccessible to the speaker's awareness, let alone to intervention by the speaker. The listener follows the same procedure, if need be, the only difference being that the questions are formulated from the listener's point of view: 'If this is what the speaker wanted to say, does the output received match that, following the rules of the language, and what choices did the speaker make when making his lexical selections, organising his sentence and choosing his stylistic and phonetic registers?'

The question of 'choices made' is important and central to the present context. Sociolinguistic research over the past half century has shown more systematically and in much greater detail than was known before that in most cases a lexical selection within the semantic space envisaged by the speaker, 
or the fixing on a phonetic register is a function of following four (1) the speech community or subcommunity the speaker is, or wishes to be considered to be, a member of, (2) the speaker's socio-economic status, (3) the speech situation and (4) the speaker's attitude with regard to that situation, including the interlocutor(s). The internal language machinery of competent speakers must, therefore, be internally variable, incorporating a finely tuned indexing system for alternative ways of expressing the same thought content or intent, each alternative being marked for values on certain regional and interactional parameters. In practical terms this means that a speaker sensu stricto, before starting to speak, 'decides', within his active competence, on the settings of the parameters concerned that he feels are most appropriate for the speech situation at hand. The scare quotes around the word decides imply that this decision is, in most cases, well below the threshold of awareness, as the speaker will need all his cognitive energy for the actual semantic content of his utterance.

For example, it is part of a normal English speaker's linguistic competence that he is, or can make himself, aware of the fact that the choice between the nouns car and vehicle largely depends on the interactional situation, just like the choice between the phonetic forms is not and ain't. Labov (1966) has famously shown that the actual realization of postvocalic $r$ in the speech of lower-middle class native New Yorkers is a function of regional origin, socio-economic status, the speech situation and the speaker's attitude with regard to that situation. In native New York vernacular, the $r$ is not pronounced but realized, roughly speaking, as a lengthening of the preceding vowel. However, when one goes up the social ladder, standard American $r$-pronunciation becomes more frequent in the speech produced (whereby the phonetic realization is itself again subject to social differentiation). The American sociolinguist William Labov found, in 1966, that the statistical incidence of $r$-pronunciation increases with the formality of the speech situation and that, in formal situations, those who normally do not pronounce their $r \mathrm{~s}$ start pronouncing them with even greater frequency than those who normally already do so to a considerable extent, owing to their higher socio-economic status (the famous 'crossover' effect). Stylistic, sociolinguistic and interactional variability and the marking of alternatives for regional and interactional values is an inherent feature of every language spoken in any sufficiently large and therefore socially differentiated language community. In the vast majority of cases, speakers make their selections unconsciously, as a matter of routine or by default, but it is, in principle, possible to raise such phenomena to a level of full consciousness.

\section{ACCOMMODATION AND DIVERGENCE IN BINARY INTERACTION}

In the wake of Labov's (1966) study of r-realization in New York English, the Englishman Howard Giles found, through precise phonetic measurements, that in binary face-to-face interaction of some duration, British speakers of different social classes or backgrounds tend to shift their sociolinguistic and interactional parameter settings as the conversation proceeds according to whether they feel positively or negatively disposed with regard to their interlocutor (Giles 1973; Giles et al. 1991). In simple terms, speakers from different social classes who have positive feelings with regard to each other tend to move their settings closer to each other, whereas speakers who have negative feelings with regard to each other start accentuating the differences 
between them, the differences becoming greater as the feelings are stronger. The terms used for the former process are accommodation or convergence; the latter process is called divergence.

In all cases observed, the speakers involved had no idea that they were accommodating (converging) or diverging, as the case might be. It all happened below the threshold of awareness. It seems justified to speak here of unconscious communication, as one has to do here with elements in the speech message that carry information - albeit of a paralinguistic kind, since the information at issue falls outside the form-meaning relationship that is defined by any specific language - without that information being picked up at a conscious level. Phenomena of this kind are ubiquitous, but they are especially marked in speech communities (such as the community of English speakers in Britain), where class and other social differences play a relatively prominent role in social interaction of all kinds. Speakers of all languages spoken at a sufficiently large scale have finely tuned antennas for picking up socially significant elements in the realization, especially the pronunciation, of the sentences of their language. These antennas do their work mostly well below consciousness - which, of course, does not mean that their influence on private and public affairs should be considered unimportant.

What happens between two speakers also happens between and within groups of speakers. When there is a negative attitude between two groups within the same speech community, it will take very little time for institutionalized speech differences to occur. Sherif and Sherif (1966) (referred to in EiblEibesfeldt 1989: 290) investigated experimentally induced group formation among initially unacquainted 11- and 12-year-old boys in a holiday camp. It was found that within two to three days, small groups of three to four boys had formed naturally, on the basis of personal preferences. The authors then assigned the boys to two new groups, intentionally separating friends. Each new group was assigned a variety of camp tasks. Within days, new group habits, attitudes and working methods developed, along with a strong sense of group pride and solidarity. Interestingly, the two groups not only had their own secrets and jokes, they also immediately developed a group-specific jargon.

As groups are larger, such processes will naturally take more time to work themselves out, not only because size takes time but also because adult speakers may be expected to be somewhat more reserved in making their less ephemeral attitudes manifest. But there can be little doubt that feelings of group identity and the existence of friendly or hostile relations between groups will be reflected in the groupwise setting of values on the sociolinguistic and interactional parameters fixed for any language or dialect. The same holds for feelings of group identity within language communities. A single use produced by a single speaker or a small group of speakers with high status in a social group or subgroup is often immediately taken over by those who are anxious to show that they belong to that (sub)group. Young people are especially susceptible to such influences, which are also often ephemeral, but exactly the same phenomenon is also regularly observed with mature speakers, and the effects may become part of the established language of the (sub)group in question.

\section{UNCONSCIOUS MASS COMMUNICATION AND LANGUAGE CHANGE}

Facts of this nature have hardly been explored systematically in linguistics. And to the extent that they have been, authors tend to cling to the obviously erroneous view that parameter settings of the kind described are the result of 
statistical frequency: the more frequent a lexical choice or a phonetic nuance occurs, so it is believed, the sooner it will become part of what counts as 'established' usage (e.g., Auer and Hinskens 2005). Not only is this circular, it is also false. It is circular because frequency effects of a linguistic alternative obviously result from the fact that the alternative in question is 'standard' for the given purpose in the given speech setting, which makes it hard to see how the same frequency effects could possibly cause that standard to come into being. It is false because people do not adapt their behaviour on the mere grounds that everyone else does the same but because adaptation gives group identity and thus safety. A person $P$ may live in a group $G$ where a behavioural (linguistic) variant $V$ is used with overwhelming frequency, yet $P$ may not wish to be associated with $G$. In such a case, $P$, being obstinate, will not follow the majority's behaviour but will stick to his own behavioural variant $U$ and even accentuate the difference between $V$ and $U$, with all the disadvantages and perils this may bring along. And in matters of pronunciation, lexical choice and style of speaking, $P^{\prime}$ s divergent behaviour will, for the most part, take place well below $P$ being in the least aware of what he is doing. Only linguists, observing and analysing $P^{\prime}$ s speech will notice what is happening and why.

The more 'scientifically' oriented human sciences are still suffering from a pernicious kind of neopositivism, which pulls out all registers in order to secure that mind and emotion are not seen to play any part in the understanding and explanation of human behaviour, including social learning processes such as the acquisition of a language, and that all behaviour and learning are seen as resulting from frequency of stimulus occurrence - a different name for the old behaviourist notion of conditioning. Amazingly, the term conditioning has been discredited, but the corresponding notion keeps cropping up under different names. That this bizarre 'horror mentis' is profoundly unscientific is an insight that seems to have great difficulty breaking through.

It is all a question of attitudes and identity feeling. The role of frequency, if present at all, can only be judged to be subordinate to attitude and identity. The elusive point at which, and the social-psychological mechanisms through which, any particular behavioural variant gets the status of 'standard' and begins to be part of one's group identity has so far remained opaque and elusive. Both linguistics and social psychology have precious little to say about this. We have here a research area that has hardly been broached. In Seuren (2013, Chapter 1) this question is discussed, whereby the term settling is introduced for that process, calling attention to the central role of attitudebased settling in processes of language change. I have, so far, found little support for this point of view in the literature. Kristiansen and Jørgensen (2005) is a lone exception, proposing the view that large scale subjective acceptance of a way of speaking is the crucial factor in language (or dialect or sociolect) change. ${ }^{3}$

In fact, the linguistic behaviour of one person or small group of persons forming a social focus or reference point may quickly infect that of a large community, even to the extent that the changes concerned reach that elusive turning point at which the results become part of what is taken to be the 'standard' within a community or subcommunity. For example, there was a time many of us will still remember, during the early 1960s, when the use of the word groovy became iconic for social protest as manifested in flower power, the hippie movement and other mild forms of anarchism. There was a sudden rise in the frequency with which this word occurred, due to the fact 
that some figure or figures who were prominent in the anti-society movement of the day had started using this word as a term of approval, first for the music produced and cultivated in their circles (and a powerful means of 'bonding'), then widened to other spheres of life. This use of the word was ephemeral, as it came and went with the movement concerned. Nowadays, only the word cool still reminds us of groovy, though cool carries far weaker associations of social protest than its ancestor groovy, no doubt because what was once a hippie movement has now been diluted and integrated into generally accepted ways of thinking and behaving, as is shown, for example, by the gradual disappearance of the necktie as part of a man's apparel. (I would not exclude that there is now a significant correlation between the use of the word cool and the absence of a necktie.)

Or, to take an example from a different time and place, the word person, derived from Latin persona, has its origin in the Roman theatre of classical times. Originally, the word persona was used for a mask as used in the theatre, covering the entire head, with expressive facial features and a large opening for the voice sound to be trumpeted freely into the audience. The original meaning was 'something through which sounds can pass', from the verb per-sonare 'make sound through'. Soon the word was used for the characters performing in a play and, in Cicero's days, for public personages in the public and political arena. The transition to the modern weakened meaning 'person' took place from there on. The question is: why and how did this word lose its theatrical meaning and come to be used for 'character', then 'person', in a general sense? First, one presumes, because there was a need for such a word, as the Latin language of the day, just as Ancient Greek, lacked a term for what we call person or personage (the Modern Greek word for 'person' is átomo, 'atom'). But then, why was this specific word selected? We do not know, but one can imagine that some public figure first used the word in a metaphorical sense for 'public figure', as if public affairs were conducted on a stage. The 'people' would have found that use witty and, above all, useful, given the lexical gap. From there on, the meaning was widened from 'public figure' to the modern 'person' - a process that took place over a much longer time. What I want to emphasize, in the present context, is that the entire development, from 'stage mask' to 'person', has been a matter of social psychology, applied to language. And this process is, in principle, unconscious and subject to a social-psychological process of standardization, the ins and outs of which have not, as yet, been disclosed.

\section{CONCLUSION}

We thus conclude that, especially in spoken linguistic interaction between two speakers, the messages often carry more than just the linguistically defined meaning telling the listener in what way the speaker has made a socially binding commitment with regard to a state of affairs depicted by, or in, the proposition expressed. Messages, especially spoken messages, also carry all kinds of information about the speaker's regional and/or socio-economic background, his attitude with respect to his interlocutor and the speech situation and other matters possibly quite unrelated to the message in question. Such 'paralinguistic' information tends to be registered well below any threshold of awareness, yet it is nonetheless real for that.

Moreover, when such unconscious paralinguistic information is uniformly distributed over two or more groups of interactants rather than single 
individuals, it may lead to a convergence or divergence of language varieties and thus to language change. The claim is that, in fact, language change is largely induced by such factors and is thus to be seen as largely the result of social settling processes applied to language, always guided and restricted by whatever innate principles hold sway over the variability of languages as the property of language communities. For this claim to be scientifically respectable, it is necessary that it be recognized that consciousness, taken in the widest possible sense, as well as its counterpart unconsciousness, should be recognized as real causal factors in human processes of all kinds, including linguistic processes. The fact that consciousness has not, so far, found an analysis and description in terms that satisfy modern criteria of science does not make the phenomenon unfit for scientific treatment. On the contrary, modern science is to be blamed for not having been able to incorporate consciousness into the scientific discourse in a principled way.

\section{REFERENCES}

Auer, P. and Hinskens, P. (2005), 'The role of interpersonal accommodation in a theory of language change', in P. Auer, F. Hinskens and P. Kerswill (eds), Dialect Change: Convergence and Divergence in European Languages, Cambridge: Cambridge University Press, pp. 335-57.

Auer, P., Hinskens, F. and Kerswill, P. (eds) (2005), Dialect Change: Convergence and Divergence in European Languages, Cambridge: Cambridge University Press.

de Saussure, F. (1916), Cours de linguistique générale/Course in General Linguistics, Paris-Lausanne: Payot.

— (1983), Course in General Linguistics, (ed. C. Bally and A. Sechehaye, trans. Roy Harris), La Salle, IL: Open Court.

Eibl-Eibesfeldt, I. (1989), Human Ethology, New York: Aldine de Gruyter.

Giles, H. (1973), 'Accent mobility: A model and some data', Anthropological Linguistics, 15: 2, pp. 87-105.

Giles, H., Coupland, J. and Coupland, N. (eds) (1991), Contexts of Accommodation: Developments in Applied Sociolinguistics, Cambridge and Paris: Cambridge University Press and Editions de la Maison des Sciences de l'Homme.

Hinskens, F., Auer, P. and Kerswill, P. (2005), 'The study of dialect convergence and divergence: Conceptual and methodological considerations', in P. Auer, F. Hinskens and P. Kerswill (eds), Dialect Change: Convergence and Divergence in European Languages, Cambridge: Cambridge University Press, pp. 1-48.

Kristiansen, T. and Jørgensen, J. N. (2005), 'Subjective factors in dialect convergence and divergence', in P. Auer, F. Hinskens and P. Kerswill (eds), Dialect Change: Convergence and Divergence in European Languages, Cambridge: Cambridge University Press, pp. 287-302.

Labov, W. (1966), The Social Stratification of English in New York City, Washington, DC: Center for Applied Linguistics.

Seuren, P. A. M. (2009), Language in Cognition: Language from Within, vol. I, Oxford: Oxford University Press.

_ (2013), From Whorf to Montague: Explorations in the Theory of Language, Oxford: Oxford University Press.

Sherif, M. and Sherif, C. W. (1966), Groups in Harmony and Tension: An Integration of Studies on Intergroup Relations, New York: Octagon Books. 


\section{SUGGESTED CITATION}

Seuren, P. (2015), 'Unconscious elements in linguistic communication: Language and social reality', Empedocles: European Journal for the Philosophy of Communication, 6: 2, pp. 185-194, doi: 10.1386/ejpc.6.2.185_1

\section{CONTRIBUTOR DETAILS}

Pieter Seuren is a Dutch linguist. He studied Linguistics, Classical Languages and Ancient History at the University of Amsterdam. He was lecturer of linguistics first at Cambridge University (1966-1970), then at Oxford University (1970-1974). From 1974 till his retirement in 1999 he held the chair, first of philosophy of language, then of theoretical linguistics, at the Radboud University in Nijmegen, Netherlands. Since his retirement he has been working as a guest researcher at the Max Planck Institute for Psycholinguistics at Nijmegen. In his work, he tries to establish a balance between an ecological and a formal approach to the phenomena of language and language use.

Contacts: Max Planck Institute for Psycholinguistics, P. O. Box 310, $6500 \mathrm{AH}$ Nijmegen, The Netherlands.

E-mail: pieter.seuren@mpi.nl

Pieter Seuren has asserted his right under the Copyright, Designs and Patents Act, 1988, to be identified as the author of this work in the format that was submitted to Intellect Ltd.

\section{NOTES}

1. I use masculine third-person pronouns in a gender-neutral sense, just as masculine nominal expressions like author, driver, painter are used gender-neutrally. I like to think that I would have done the same if I had been a woman.

2. The five conscious interface levels proposed plus the hidden machinery linking them up would seem to contradict the common fact that, normally speaking, both the production and the comprehension of utterances proceed relatively, or, if you like, very, rapidly, which might seem strange in view of the complexity of the underlying system. It must be remembered, however, that the formal system is fully automatized and also that actual coherent discourse is regulated by a topic-comment (or 'old-new') structure, whereby the topic is provided by preceding context (or the speech situation) and the comment consists in providing the topic with a predicate constituting new information. This implies that the linguistic expression corresponding to the (old) topic has already been processed by both speaker and listener, so that only the (new) comment remains to be processed when the utterance is produced or interpreted. See Seuren (2009: 238) for further discussion.

3. In this context, it is not surprising to see that languages of nations with a strong and historically ingrained sense of unified national identity and a corresponding weak sense of regional identity show relatively little dialect variation. This is typically so for Turkish, spoken by a nation with a long tradition of strong nationalism. Although Turkey's geography meets all conditions for great dialectal variation (large distances through thinly populated areas, great regional isolation), dialectal variation within Turkish as a national language is minimal compared with the languages of other nations. 